POLITICAL CONTRIBUTION AND

POLICY - SOME EXTENSIONS

by

Benjamin Bental and Uri Ben-Zion

Discussion Paper No. 75-55, June 1975

\author{
Center for Economic Research \\ Department of Economics \\ University of Minnesota \\ Minneapolis, Minnesota 55455
}


POLITICAL CONTRIBUTION AND POLICY - SOME EXTENSIONS

by

Benjamin Bental and Uri Ben-Zion *

The effect of political contribution on votes and polfcy was analyzed in a recent work of $U$. Ben-zion and $Z$. Eytan, using a simple economic mode $1^{1}$ of the political process. The purpose of this work is to extend the above model to some additional cases which we consider relevant in the complicated political world.

The first section discusses the case of an "honest" politician who considers his own subjective preference in his polfcy decision in an election campaign. The second section deals with a non-homogeneous voting population and considers the distinction between "loyal voters" and "undecided voters". This discussion follows earlier work of J. S. Coleman $(1971,1972)$ who emphasized the role of parties in optimal policy decision in a democracy. The third section formally analyzes the allocation of the firm's contributions between candidates. Finally, Section IV sumarizes the conclusions.

I. The Role of the Candidate's Subjective Preferences

In Ben-Zion and Eytan the candidate is assumed to choose the policy variable which will maximize the number of votes for his candidacy. He has no opinion of his own which he wishes to promote and he adjusts 
himself to the medium stand of his voters. In this approach we compare a political leader to a business entrepeneur who maximizes an objective measure of a firm's profit and his decision on business policy does not depend on any subjective taste.

The view of a political leader as a "spinless opportunist" may be regarded by some political scientists as an unfair description of the political process, and we may want to consider a modification of the approach.

An alternative interpretation to this assumption of Ben-zion and Eytan is that there is a very large number of alternative party leaders who have a different vector of personal preferences along the relevant range of the policy dimension. It can be assumed that the party chooses an objective policy point in the space of the relevant party variable so as to maximize the number of votes. The specific leader is then selected as the individual whose own subjective preferences come closest to the party objective policy vector. In this approach the candidate is an "honest" citizen whose personal taste happens to be the one selected by the party technicians.

One implication of the above interpretation is that changes in party policy as a result of increase in contributions, will be associated with an appropriate change in the leader. This implication is not consistent with an observed phenomena that party leaders tend quite of ten to change their own policy rather than resign from their political jobs. 
On the other hand, observations indicate that sometimes "honest politicians" choose to resign rather than make a complete change in their own policy statements.

We can relax the "opportunism" assumption by introducing a candidate's utility function ${ }^{2} U(P, S, \mu)$, where $P$ denotes the percentage of votes the candidate expects to gain, $X$ is his own stand and $\mu$ the platform which the candidate will eventually take to the public. Let $\mathrm{X}$ be to the left of $\mu$ so that $x-\mu$ is negative. Further we assume that marginal utilities are positive and decreasing. 3

(1)

$$
\begin{aligned}
& \frac{\partial U}{\partial P}>0 \\
& \frac{\partial U}{\partial(X-\mu)}>0 \\
& \frac{\partial^{2} U}{\partial P^{2}}<0 \\
& \frac{\partial^{2} U}{\partial(X-\mu)^{2}}<0 .
\end{aligned}
$$

Our candidate wishes to maximize his utility, taking into account the following relationships: the percentage of the votes he gains is higher the nearer he is with his platform to the voters' stand (denoted by $z$ ) and the higher the amount of contributions (M) he can attract. The latter is a function of the candidate's platform and the contributors stand $(\mathrm{Y})$. 
Putting this down formally, we get the following:

$$
\begin{array}{ll}
\text { (2) } \quad \operatorname{Max} & \{U(P, X-\mu)\} \\
\text { (2.a) } & P=P(\mu-Z, M) \\
\text { (2.b) } & M=M(Y-\mu) .
\end{array}
$$

Substitution of the constraints (2.a) and (2.b) into the maximand yields (2') $\quad \operatorname{Max}\{U(P(\mu-Z, M(Y-\mu)), X-\mu)\}$

by differentiation of $U$ with regard to $\mu$ we have as a necessary condition for maximum

$$
\frac{d U}{d_{\mu}}=\frac{\partial U}{\partial P}\left[\frac{\partial P}{\partial(\mu-Z)}-\frac{\partial P}{\partial M} \cdot \frac{\partial M}{\partial(Y-\mu)}\right]-\frac{\partial U}{\partial(X-\mu)}=0
$$

or

(4) $\frac{\frac{\partial U}{\partial(X-\mu)}}{\frac{\partial U}{\partial P}}=\frac{\partial P}{\partial(\mu-Z)}-\frac{\partial P}{\partial M} \cdot \frac{\partial M}{\partial(Y-\mu)}$.

The left hand side of (4) is positive. We assume that $\frac{\partial P}{\partial(\mu-Z)}<0$ and $\frac{d M}{d(Y-\mu)}<0$ and that the larger the sum of money contributed, the higher the percentage of votes the candidate can expect to gain: $\frac{\partial P}{\partial M}>0$. Thus, for (4) to hold, it is a necessary condition that:

(5) $\quad \frac{\partial P}{\partial(\mu-Z)}<-\frac{\partial P}{\partial M} \cdot \frac{\partial M}{\partial(Y-\mu)}$.

(5) means that the rate of gaining votes resulting from the larger contributions must be, at the optimum, greater than the loss of votes 
he suffers from a change in policy which widens the gap between the candidate and the public. If (5) does not hold, it will be non-optimal for the candidate to "trade" his policy for contributions.

In the simple case where the utility function depends only on the probability of success $P$, the left hand side of (4) is zero. The condition can then be interpreted that the candidate's platform should be such that any loss of votes due to a change in a policy variable towards unpopular contributors will be offset by the votes that can be expected to be gained through monetary contributions obtained by this move. ${ }^{4}$

Our results indicate that if a candidate's utility function also depends on the policy he recommends, $x$, then the candidate will move by a contribution towards an unpopular direction only when he expects sufficient net gain in votes, which will compensate for the loss of personal utility he suffers from the undesired move. The "honest politician" considered in this case is therefore more expensive to buy than the opportunistic one. 5

On the other hand, a "too honest" politician for which the subjective rate of transformation $\frac{\partial U}{\partial(X-\mu)} / \frac{\partial U}{\partial P}$ is high, may not survive in the real world. He might charge such a high price for policy changes, which will leave him unable to obtain sufficient contributions and, as a result, will significantly reduce his probability of being elected. The maximization of utility will mean either a decision to quit politics or to be a constant loser. 
The comparison between the "honest" and the "opportunist" politicians can be shown diagramatically in Figure 1. An opportunist maximizes the probability of winning $P$, which is a function of the candidate's stand $\mu$. in' denotes the optimal policy. The honest candidate maximizes his utility $\mathrm{U}(\mathrm{P}, \mathrm{X}-\mu)$, and the indifference curves are shown in the diagram. The optimal point of the honest candidate is at $\mu^{*}$ where the indifference curve is tangent to the $P(\mu)$ curve. $^{6}$

\section{Figure 1}

One interesting implication of (4) is that if the candidate has resources which are not tied to a change in policy, the marginal productivity of additional money in the production function of votes $\left(\frac{\partial P}{\partial M}\right)$ declines and the candidate will make a smaller change in his policy for a given contribution per policy change. This suggests that the allocation of "good money" from public resources to campaign financing may reduce the influence of "bad money" which is tied to a non-optimal change in policy from society's point of view. 7

The second order condition indicates that under reasonable assumptions $^{8}$ (4) represents a maximum. However in the case where contributions grow in an increasing rate, the candidate may have an incentive to identify his policy with the contributor's stand, and (4) represents a minimum. 
$-6 a-$

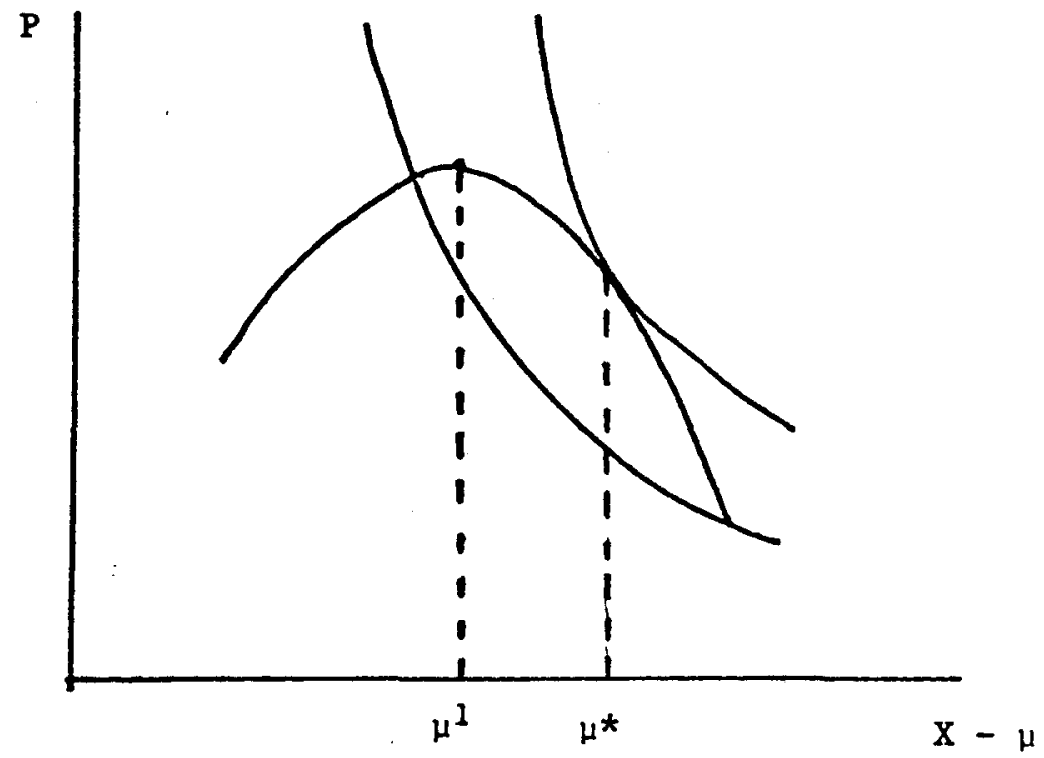

Figure 1: Comparison of "honest" and "opportunistic" candidates. 
II. A Political Model with Conservative Voters

The previous section analyzes the policy choice of one candidate, disregarding the role of the "parties" in the analysis. In this section we analyze the choice of policy by a candidate in a more realistic political environment. 9

For simplicity we discuss one political issue, where voters are divided into three groups with regard to their policy. Groups A and B are extreme orthodox groups, who will vote only for their candidates 1 and 2 respectively. Each member of these groups may also choose not to vote, but he will never consider a vote for the alternative candidate. The third group, $C$, consists of undecided voters, whose choice will depend, among other things, on the candidate's policy as well as on his campaign funds and his ability to clarify and justify his stand.

We assume that a decision of the "loyal" voters to vote (for the candidate of the party) or not to vote (to be absent) depends on the distance between the candidates' views. When a candidate narrows the gap to his rival he loses ever growing proportions of his own followers $\left(P_{A}\right)$ but he also reduces the percentage of his opponent's followers. Our assumption that money does not affect the orthodox voters means that they are we11 informed and do not need advertising messages and other policy campaign instruments. The undecided voters in group $C$ are, on the other hand, affected positively by the money which the candidate has on hand. 
We sha11 use the following notations:

$P_{A}$ - percentage of members of group A voting for candidate 1.

$P_{B} \quad$ - percentage of members of group B voting for candidate 2.

$\mathbf{P}_{C}^{1} \quad$ - percentage of members of group $C$ voting for candidate 1.

$P_{C}^{2} \quad$ - percentage of members of group $C$ voting for candidate 2.

$\mathrm{V}_{\mathrm{A}}$ - number of voters in group $A$.

$\nabla_{B}$ - number of voters in group $B$.

$\mathrm{V}_{\mathrm{C}}$ - number of voters in group $C$.

$\mu_{1}$ - platform of candidate 1.

$\mu_{2}$ - platform of candidate 2 .

Z - stand of group C.

$N_{1}$ - numbers of votes for candidate 1 .

$\mathrm{N}_{2}$ - numbers of votes for candidate 2.

Hence:

(6)

$$
\begin{aligned}
& N_{1}=P_{A}\left(\mu_{2}-\mu_{1}\right) \cdot V_{A}+P_{C}^{1}\left(Z-\mu_{1}, M_{1}\left(\mu_{1}\right)\right) \cdot V_{C} \\
& N_{2}=P_{B}\left(\mu_{2}-\mu_{1}\right) \cdot V_{B}+P_{C}^{2}\left(Z-\mu_{2}, M_{2}\left(\mu_{2}\right)\right) \cdot V_{C}
\end{aligned}
$$

We shall analyze candidate 1 . He wishes to maximize the percentage of the votes given to him:

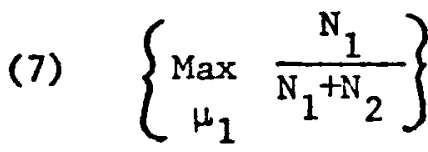


Differentiating in respect to $\mu_{1}$, we obtain:

(8)

$$
\frac{-\frac{d P_{A}}{d\left(\mu_{2}-\mu_{1}\right)} v_{A}+\left[-\frac{\partial P_{C}^{1}}{\partial\left(Z-\mu_{1}\right)}+\frac{\partial P_{C}^{1}}{\partial M_{1}} \cdot \frac{d M_{1}}{d_{\mu_{1}}}\right] v_{C}}{-\frac{d P_{B}}{d\left(\mu_{2}-\mu_{1}\right)}}=\frac{N_{1}}{N_{2}}
$$

This can also be written as

$$
\frac{\frac{d P A}{d\left(\mu_{2}-\mu_{1}\right)} V_{A}+\left[-\frac{\partial P_{C}^{1}}{\partial\left(Z-\mu_{1}\right)}+\frac{\partial P_{C}^{1}}{\partial M_{1}} \cdot \frac{d M_{1}}{d \mu_{1}}\right] V_{C}}{N_{1}}=-\frac{\frac{d P_{B}}{d\left(\mu_{2}-\mu_{1}\right)}}{N_{2}}
$$

The left hand side of (9) represents the relative increase of votes through a change in the candidate's policy, calculated as the difference between the gain of undecided voters minus the loss of orthodox followers. The right hand side represents the relative loss of the second candidate as a result of change in the first candidate's policy. The equilibrium condition indicates that a candidate does not necessarily maximize the number of votes. He may rather lose votes by moving towards the middle group, if by moving he causes a higher loss of votes to the other candidate. In equilibrium a marginal percentage of votes he loses is equal to the marginal percentage of votes lost by his rival. From (9) we can see that the rate of the candidate's move towards the center will depend on: 
(a) The size of his basic group of followers $\left(V_{A}\right)$; a candidate with a smaller group will move more towards center.

(b) The response of his group (measured by $\frac{d p_{A}}{d\left(\mu_{2}-\mu_{1}\right)}$ ) to his move. The candidate will move more towards the center if the group is more willing to accept his change in policy, without a significant reduction in their political support. If the group is more extreme in a sense that it may consider a move to the center as a betrayal, the candidate will stick more to his group.

(c) The response of the center group $\frac{\partial P_{C}^{1}}{\partial\left(Z-\mu_{1}\right)}$.

The higher the group response in terms of the increased voting for the candidate $\left(\frac{\partial P_{C}}{\partial\left(Z-\mu_{1}\right)}\right)$, the more he will move to the center.

(d) The response of his rival's followers $\frac{\partial P_{B}}{\partial\left(\mu_{2}-\mu_{1}\right)}$, if the rival's followers are more responsive to his policy changes he will move more towards the center.

The role of money in this campaign depends on the sign of $\frac{d M_{1}}{d_{\mu_{1}}}$. If $\frac{d M_{1}}{d_{\mu_{1}}}>0$, which means that the contributors are mainly from the center group, then he will move more towards the center. If, however, important contributors are members of the candidate's group, then $\frac{\mathrm{dM}_{1}}{\mathrm{~d}_{\mu_{1}}}<0$, and the candidate will remain close to his own group and use the money from contributions to influence the undecided center. If the orthodox group (say A) expects a high degree of loyalty from its candidate, such that $\frac{\partial P_{A}}{\partial\left(\mu_{2}-\mu_{1}\right)}$ is relatively $h i g h$, then it 
can keep the candidate close; yet his chances of winning depend strongly on this group's votes and its contributions to his campaign. However, if the group requires loyalty, but has no money, then its main effect will be to impose a strong restriction on the candidate's campaign and policy and thus reduce significantly his influence on the center group. If, in addition, the candidate's group is relatively small, then his chances to win the election are slim. The case of the McGovern candidacy in 1972 seems to fall into this particular category.

In second order condition indicates that (9) represents a maximum only if the partial effect of moving towards the center and opposite groups increases the candidate's proportion of votes by less than the loss incurred by moving away from his group. 10

\section{Allocation of Contributions by the Firm}

In Section I we examined the optimal policy of a candidate by whose policy influenced the amount of money he received as contributions. Now we wish to examine the contributor's problem for an investment contribution. 11

We assume there are two candidates the contributor may support, and a given sum of money he can spend (Mo). The contributor has a political stand (denoted by $Y$ ), and he wishes to pull the candidates as close as possible to this stand by "buying" them - the more money he gives the closer the candidates platform $(\mu)$ will get to Y. ${ }^{12}$ 
The conditional profit from a contribution to a given candidate (should he be elected) is a function of the policy chosen by the candidate.

$$
\pi_{i}=\pi_{i}\left(Y-\mu_{i}\left(M_{i}\right)\right) \text {, }
$$

where $\mu_{i}$ denotes the position chosen by the candidate $i$ which is a function of the contribution $M_{1}$.

The firm is assumed to maximize its expected gain from its contributions to the two candidates:

$$
\begin{aligned}
& \underset{M_{1}}{\operatorname{Max}}\left\{G=P_{1}\left(M_{1}+m_{1}, M_{2}+m_{2}\right) \cdot \pi_{1}\left(Y-\mu_{1}\left(M_{1}\right)\right)+\right. \\
& \left.+P_{2}\left(M_{1}+m_{1}, M_{2}+m_{2}\right) \cdot \pi_{2}\left(Y-\mu_{1}\left(M_{2}\right)\right)-M_{0}\right\} \\
& M_{1}+M_{2}=M_{0} \\
& \mathrm{P}_{1}+\mathrm{P}_{2}=1 \text {, }
\end{aligned}
$$

where $m_{1}$ and $m_{2}$ denote the amount of money the candidates have from other contributions (which are assumed to be given). ${ }^{13} M_{1}, M_{2}$ denote the contributions by the given firm.

Substituting the constraints with the maximand we obtained,

$\operatorname{Max}_{\mu_{1}}\left\{G=\bar{P}_{1}\left(M_{1}\right) \cdot \pi_{1}\left(Y-\mu_{1}\left(M_{1}\right)\right)+\left(1-\bar{P}_{1}\left(M_{1}\right)\right) \cdot \pi_{2}\left(Y-\mu_{2}\left(M_{0}-M_{1}\right)\right)-M_{0}\right\}$ 
where $\bar{P}_{1}$ is a reduced form representation of the winning probability of candidate 1 .

Differentiation of (11)' yields:

(12) $\frac{\partial \bar{P}_{1}}{\partial M_{1}} \cdot \pi_{1}-\bar{P}_{1} \frac{\partial \pi_{1}}{\partial\left(Y-\mu_{1}\right)} \cdot \frac{\partial \mu_{1}}{\partial M_{1}}=\frac{\partial \bar{P}_{1}}{\partial M_{1}} \cdot \pi_{2}-\left(1-\bar{P}_{1}\left(M_{1}\right)\right) \cdot \frac{\partial \pi_{2}}{\partial\left(Y-\mu_{2}\right)} \cdot \frac{\partial \mu_{2}}{\partial\left(M_{0}-M_{1}\right)}$

We assume that $\frac{\partial \bar{P}}{\partial M}>0, \frac{\partial \pi}{\partial(Y-\pi)}<0, \frac{\partial \mu}{\partial M}>0$.

The left hand side of (12) can be interpreted as the marginal return contribution to candidate 1. Similarly, the right hand side is the marginal profit of contribution to candidate $2^{14}$ (12) means that marginal profit should be equated.

Since a money contribution to a candidate affects its gain from favorable regulation ${ }^{15}$, we can use the technique and terminology of a firm. demand for factor of production. The allocation of contributions to the candidates is therefore analogous to the allocation of a given factor of production in two production activities.

$\frac{\partial\left[P_{1}-\pi_{1}\left(Y-\mu_{1}\left(M_{1}\right)\right)\right]}{\partial M_{1}}$ is the expected marginal revenue product (MRP) of the firm's dollar of contribution to candidate 1 , and $\frac{\partial\left[\mathrm{P}_{2}-\pi_{2}\left(\mathrm{Y}-\mathrm{H}_{2}\left(\mathrm{M}_{2}\right)\right)\right]}{\partial M_{2}}$ is MRP of a contribution to candidate 2 .

The optimal allocation of contributions to the two candidates is determined by the aggregate marginal revenue product, which is given as a horizontal sumation of the individual MRP. This is given in Figure 2 . 
Figure 2

It is clear from the diagram that if the firm has a small amount of money to contribute, it will invest it only in the "best candidate" from the firm's point of view. If a candidate has a high probability of winning and is sensitive to the firm's contributions, then the firm may invest only in this candidate. If the firm decides to increase the level of political contributions, it may contribute to the other candidate, due to the decreasing nature of the marginal revenue product. Similarly, if candidate 2 is far from $Y$ and unfavourable to the contributor $\left(\pi_{2}\right.$ or $\frac{\partial \pi_{2}}{\partial\left(Y-\mu_{2}\right)}$ are very sma11), it is likely that the marginal profit of money given to candidate 1 will always exceed the marginal profit of money given to candidate 2 , and therefore candidate 2 will not be supported.

In a more realistic case of a democratic society, a policy is not determined solely by the winning party, but will also depend on the stands of other parties in the political arena (see Stigler).

This approach to the political process suggests that the actual policy and the realized profit will depend on the views of both candidates.

The firm may wish to maximize the gain from political contributions. 


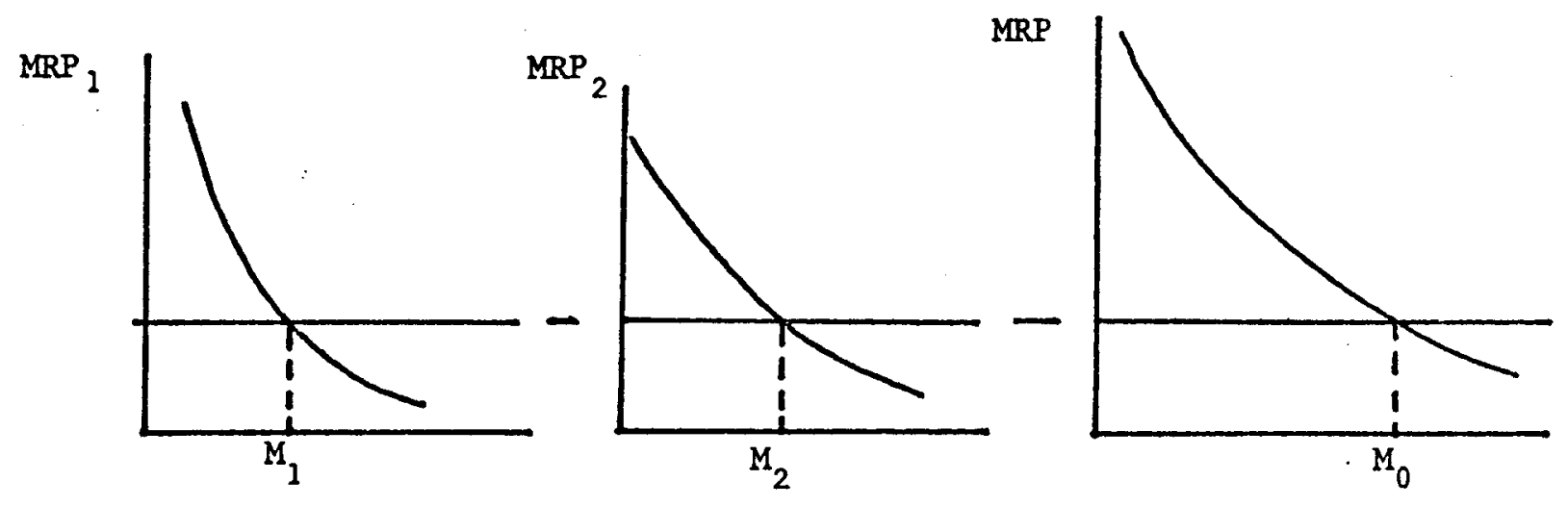

Figure 2: The aggregation of marginal revenue product and the optimal allocation of contributions. 
(13)

$$
\begin{aligned}
\operatorname{Max}\{G & =P_{1}\left(M_{1}, M_{2}\right) \cdot \pi_{1}\left(Y-\mu_{1}\left(M_{1}\right), Y-\mu_{2}\left(M_{2}\right)\right)+ \\
& \left.+P_{2}\left(M_{1}, M_{2}\right) \cdot \pi_{2}\left(Y-\mu_{1}\left(M_{1}\right), Y-\mu_{2}\left(M_{2}\right)\right)-M_{0}\right\}
\end{aligned}
$$

subject to the following constraints.

$$
\begin{aligned}
& M_{1}+M_{2}=M_{0} \\
& P_{1}+P_{2}=1 .
\end{aligned}
$$

By similar mathematical manipulations as in the "simple" case we obtain:

$$
\begin{aligned}
\frac{\partial \overline{\mathrm{P}}_{1}}{\partial \mathrm{M}_{1}} & \cdot \pi_{1}-\frac{\partial \mu_{1}}{\partial \mathrm{M}_{1}}\left[\overline{\mathrm{P}}_{1} \frac{\partial \pi_{1}}{\partial\left(\mathrm{Y}-\mu_{1}\right)}+\left(1-\overline{\mathrm{P}}_{1}\right) \frac{\partial \pi_{2}}{\partial\left(\mathrm{Y}-\mu_{2}\right)}\right] . \\
& =\frac{\partial \overline{\mathrm{P}}_{1}}{\partial \mathrm{M}_{1}} \cdot \pi_{2}-\frac{\partial \mu_{2}}{\partial\left(\mathrm{M}_{0}-\mathrm{M}_{1}\right)}\left[\overline{\mathrm{P}}_{1} \frac{\partial \pi_{1}}{\partial\left(\mathrm{Y}-\mu_{1}\right)}+\left(1-\overline{\mathrm{P}}_{1}\right) \frac{\partial \pi_{2}}{\partial\left(\mathrm{Y}-\mu_{2}\right)}\right] .
\end{aligned}
$$

The marginal revenue product of a contribution to one candidate (say 1) will depend in this case on the change in his policy if elected and on its influence on the rival's policy if he is not elected. In comparison to (12), it can be seen that if the sensitivity of one candidate to his opponent's stand is high enough, it will induce a transfer of contributions to the second candidate.

\section{Concluding Note}

We tried in this paper to analyze some aspects of the political process by means of economic models. We hope that this approach may prove to be relevant in further analyzing the relationship between policy and contributions in a democratic society. 


\section{FOOTNOTES}

* The authors are graduate student, University of Minnesota, and Senior Lecturer, Technion, Israel, Institute of Technology. We wish to thank Professor Gordon Tullock for comments and suggestions, and Barbara Oehlert for assistance. Financial support of the American Telephone and Telegraph Company is gratefully acknowledged.

1) For further work on this topic, see R. J. Barro, H. R. Peniman and R. K. Winter, G. J. Stigler, G. Tullock, and W. P. Welch.

2) We assume the function to be separable in its arguments.

3) For simplicity we assume that the public's stand $z$, the contributor's stand $\mathrm{Y}$ and the candidate's stand $\mathrm{X}$ are ordered in one direction, and $\mathrm{Y}$ is the right $\mathrm{Z}$ and $\mathrm{X}$.

4) See also Ben-Zion and Eytan, page 6.

5) It should be emphasized that the main reason our candidate is looking for money is because voters are strongly influenced by money-intensive operations. If voters were willing to spend their own time and resources to learn the policy of a candidate, then the marginal productivity of money in the production of votes would decline and even an "opportunistic" candidate would find it less desirable to "sel1" his policy variables. 
6) This curve can be regarded as a possibility frontier which is determined by the production process of votes.

7) This implication is more general and is not specific to this section.

8) We assume the sign of the second order derivative of $P$ with respect to $\mu$ to be negative; that is, the voters get more and more annoyed with the candidate the further $\mu$ is from $z$.

9) For an analysis of the effect of political parties on the optimal Policy Decision, see Coleman; he, however, does mot consider the role of campaign contributions which has been introduced in our analysis.

10) Formally the second order condition is:

$$
\begin{aligned}
& \mathrm{N}_{2}\left(\frac{\partial^{2} \mathrm{P}_{\mathrm{A}}}{\partial \mu_{1}^{2}} \mathrm{~V}_{\mathrm{A}}+\frac{\partial^{2} \mathrm{P}_{\mathrm{C}}^{1}}{\partial \mu_{1}^{2}} \mathrm{~V}_{\mathrm{C}}\right)-\mathrm{N}_{1} \frac{\partial^{2} \mathrm{P}_{\mathrm{B}}}{\partial \mu_{1}^{2}} \mathrm{~V}_{\mathrm{B}}<0 \text {, where } \\
& \frac{\partial^{2} \mathrm{P}_{\mathrm{A}}}{\partial \mu_{1}^{2}}<0, \frac{\partial^{2} \mathrm{P}_{\mathrm{B}}}{\partial \mu_{1}^{2}}<0, \frac{\partial^{2} \mathrm{P}_{\mathrm{C}}}{\partial \mu_{1}^{2}}>0 .
\end{aligned}
$$

11) "Quid Pro Quo" contributor in Welch Terminology.

12) We assume that $Y$ is to the right of $\mu$. See Section $I$. 
13) Since the effect of the candidates' own resources was already discussed, we omit $m_{1}$ and $m_{2}$ from the analysis.

14) This is easy to show if one remembers the relationship $P_{2}\left(M_{2}\right)=1-\bar{P}_{1}\left(M_{0}-M_{1}\right)$.

15) See Stigler, (1972). 
REFERENCES

Barro, Robert J., "The Control of Politician: An Economic Mode1" Public Choice, Vo1. XIV (Spring 1973) pp. 19-42.

Ben-Zion, Uri and Zeev Eytan, "On Money, Votes and Policy in a Democratic Society", Public Choice, Vol. XVII,(Spring 1974) pp. 1-10.

Coleman, James S., "The Position of Political Parties in Elections" in Probability Models of Collective Decision-Making, Richard G. Niemi and Herbert F. Weisberg (eds.) Charles E. Merrill Publishing Company, Columbus Ohio, 1972.

Coleman, James S., "Internal Processes Governing Party Position in the Elections", Public Choice, Vol. XI (Fa11, 1971) Pp. 35-60.

Peniman, Howard R. and Ralph K. Winter, Campaign Finances: Two Views of the Political Implications, New York, American Enterprise Institute for Public Research, 1971.

Stigler, George J., "The Theory of Economic Regulation", The Bell Journal of Economics and Management Sciences, Vol. 2 (Spring 1971) Pp. 3-21.

Stigler, George J., "Economic Competition and Political Competition", Public Choice, Vol. XIII (Fall 1972) pp. 91-106.

Tullock, Gordon, "The Purchase of Politician", Western Economic Journal, Vol. X, (September 1972) pp. 354-355.

Welch, William P., "The Economics of Campaign Funds", Public Choice, Vol XX (Winter 1974), pP. 85-97. 